\title{
Interaction between structurally different heteroexopolysaccharides and -lactoglobulin studied by solution scattering and analytical ultracentrifugation
}

Khan, Sanaullah; Birch, Johnny; Van Calsteren, Marie-Rose; Ipsen, Richard; Peters, Günther H.J.; Svensson, Birte; Harris, Pernille; Almdal, Kristoffer

Published in:

International Journal of Biological Macromolecules

Link to article, DOI:

10.1016/j.ijbiomac.2018.01.050

Publication date:

2018

Document Version

Peer reviewed version

Link back to DTU Orbit

Citation (APA):

Khan, S., Birch, J., Van Calsteren, M-R., Ipsen, R., Peters, G. H. J., Svensson, B., Harris, P., \& Almdal, K. (2018). Interaction between structurally different heteroexopolysaccharides and -lactoglobulin studied by solution scattering and analytical ultracentrifugation. International Journal of Biological Macromolecules, 111, $746-754$. https://doi.org/10.1016/j.ijbiomac.2018.01.050

\section{General rights}

Copyright and moral rights for the publications made accessible in the public portal are retained by the authors and/or other copyright owners and it is a condition of accessing publications that users recognise and abide by the legal requirements associated with these rights.

- Users may download and print one copy of any publication from the public portal for the purpose of private study or research.

- You may not further distribute the material or use it for any profit-making activity or commercial gain

- You may freely distribute the URL identifying the publication in the public portal 


\section{Accepted Manuscript}

Interaction between structurally different

heteroexopolysaccharides and $\beta$-lactoglobulin studied by solution scattering and analytical ultracentrifugation

Sanaullah Khan, Johnny Birch, Marie-Rose Van Calsteren, Richard Ipsen, Günther H.J. Peters, Birte Svensson, Pernille

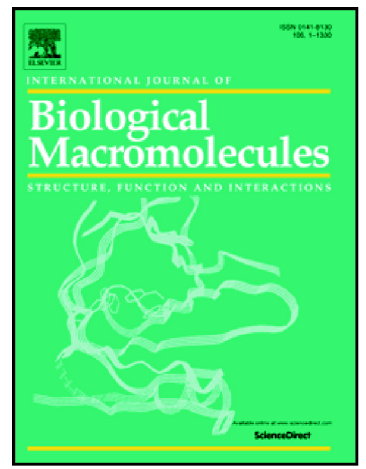
Harris, Kristoffer Almdal

PII:

S0141-8130(17)34943-7

DOI: https://doi.org/10.1016/j.ijbiomac.2018.01.050

Reference: BIOMAC 8882

To appear in:

Received date:

12 December 2017

Revised date: 24 December 2017

Accepted date:

8 January 2018

Please cite this article as: Sanaullah Khan, Johnny Birch, Marie-Rose Van Calsteren, Richard Ipsen, Günther H.J. Peters, Birte Svensson, Pernille Harris, Kristoffer Almdal , Interaction between structurally different heteroexopolysaccharides and $\beta$-lactoglobulin studied by solution scattering and analytical ultracentrifugation. The address for the corresponding author was captured as affiliation for all authors. Please check if appropriate. Biomac(2017), https://doi.org/10.1016/j.ijbiomac.2018.01.050

This is a PDF file of an unedited manuscript that has been accepted for publication. As a service to our customers we are providing this early version of the manuscript. The manuscript will undergo copyediting, typesetting, and review of the resulting proof before it is published in its final form. Please note that during the production process errors may be discovered which could affect the content, and all legal disclaimers that apply to the journal pertain. 


\section{Interaction between structurally different heteroexopolysaccharides and}

\section{$\beta$-lactoglobulin studied by solution scattering and analytical}

\section{ultracentrifugation}

Sanaullah Khan ${ }^{\mathrm{a}, \mathrm{b}, *}$, Johnny Birch ${ }^{\mathrm{a}}$, Marie-Rose Van Calsteren ${ }^{\mathrm{c}}$, Richard Ipsen ${ }^{\mathrm{d}}$, Günther H.J. Peters ${ }^{\mathrm{e}}$, Birte Svensson $^{\mathrm{a}}$, Pernille Harris ${ }^{\mathrm{e}}$ and Kristoffer Almdal ${ }^{\mathrm{b}}$

${ }^{a}$ Enzyme and Protein Chemistry, Department of Biotechnology and Biomedicine, Technical University of Denmark, Søltofts Plads, Building 224, DK-2800 Kgs. Lyngby, Denmark.

${ }^{b}$ Department of Micro- and Nanotechnology, Technical University of Denmark, Ørsteds Plads, Building 423, DK-2800 Kgs. Lyngby, Denmark.

${ }^{c}$ Saint-Hyacinthe Research and Development Centre, Agriculture and Agri-Food Canada, 3600 Casavant Boulevard West, Saint-Hyacinthe, Quebec J2S 8E3, Canada.

${ }^{\mathrm{d}}$ Department of Food Science, University of Copenhagen, Rolighedsvej 26, DK-1958 Frederiksberg, Denmark.

e Department of Chemistry, Technical University of Denmark, Kemitorvet, Building 207, DK-2800 Kgs. Lyngby, Denmark.

*Corresponding Author: phone: +4545252795; fax:+4545884922; Email: sank@ dtu.dk 


\section{Abstract}

Despite a very large number of bacterial exopolysaccharides have been reported, detailed knowledge on their molecular structures and associative interactions with proteins is lacking. Small-angle X-ray scattering, dynamic light scattering and analytical ultracentrifugation (AUC) were used to characterize the interactions of six lactic acid bacterial heteroexopolysaccharides (HePS-1-HePS-6) with $\beta$ lactoglobulin (BLG). Compared to free HePSs, a large increase in the X-ray radius of gyration $R_{\mathrm{G}}$, maximum length $L$ and hydrodynamic diameter $d_{\mathrm{H}}$ of HePS-1-HePS-4 mixed with BLG revealed strong aggregation, the extent of which depended on the compact conformation and degree of branching of these HePSs. No significant effects were observed with HePS-5 and HePS-6. Turbidity and AUC analyses showed that both soluble and insoluble BLG-HePS complexes were formed. The findings provide new insights into the role of molecular structures in associative interactions between HePSs and BLG which has relevance for various industrial applications.

Keywords: $\beta$-lactoglobulin, heteroexopolysaccharides; aggregation; small-angle X-ray scattering; dynamic light scattering; analytical ultracentrifugation.

Abbreviations: AUC, analytical ultracentrifugation; BLG, $\beta$-lactoglobulin; BMM, basal minimum medium; DLS, dynamic light scattering; EPS, exopolysaccharide; HePS, heteroexopolysaccharide; HoPS, homoexopolysaccharide; LAB, lactic acid bacteria; SAXS, small-angle X-ray scattering; SEC, size-exclusion chromatography; TCA, trichloroacetic acid. 


\section{Introduction}

Exopolysaccharides (EPSs) are extracellular carbohydrate biopolymers produced and secreted by a wide range of microorganisms including yeasts, molds, microalgae and bacteria [1-4]. EPSs produced by lactic acid bacteria (LAB) have wide diversity in structure, molecular mass, monosaccharide composition and glycosidic linkages, which confers unique physical properties [5-7]. LAB EPSs occur as homoexopolysaccharides (HoPSs) consisting of a single type of monosaccharide residues or as heteroexopolysaccharides (HePSs) that contain different monosaccharides forming repeat units $[6,8]$. Both HoPSs and HePSs are branched or unbranched complex biopolymers [6,9]. In their natural environment, LAB EPSs are believed to protect microbial cells against desiccation, phagocytosis, antibiotics and environmental stress, and they are also involved in adhesion to solid surfaces, biofilm formation and cell recognition [10-13].

Nowadays, there is increasing interest in industrially applicable biopolymers, and bacterial EPSs have significant commercial application in the food and pharmaceutical industry due to their technological functionality and GRAS ("generally regarded as safe") status [4,6]. In the food industry, LAB HePSs are mostly used to improve the physical stability and rheological properties of fermented dairy products $[4,12,14]$. The mechanism of how bacterial HePSs interacts with and influence the properties of milk proteins is poorly understood, but it is presumably associated with the specific structural characteristics of a given HePS (monosaccharide composition, molecular weight, degree of branching, nature of glycosidic linkages, charge and chain stiffness) as well as the ability to interact with proteins at low $\mathrm{pH}$ [15-18]. The functional and rheological properties of HePSs are related to their water-binding capacity and their molecular interactions with proteins [19,20], and these can be related to syneresis, viscosity, stiffness, body firmness, creaminess and a shiny surface of fermented dairy products [21]. Ayala-Hernández et al. have shown that the HePS from Lactococcus lactis ssp. cremoris 
JFR1 forms a network with heat-aggregated whey proteins at low $\mathrm{pH}$ [22]. Surface plasmon resonance studies have shown that the binding capability of HoPSs with milk proteins varies according to the type of glycosidic linkage, degree of branching and molecular size, and that the binding decreased with increasing $\mathrm{pH}$ from 4.0 to 5.5 [23,24]. Bacterial EPSs have also been used as thickener and suspension stabilizer in many pharmaceutical creams and suspensions, and more recently as a potential drug delivery system $[3,25,26]$.

EPSs extracted from bacterial sources have many advantages over plant, algal and animal polysaccharides, since their production can take place in a controlled and reproducible environment with high purity and viable economic cost value [27-29]. In the present study, we characterized six structurally different purified LAB HePSs (HePS-1-HePS-6) from Lactobacillus delbrueckii ssp. bulgaricus NCIMB 702483 [30], Lactobacillus rhamnosus GG (ATCC 53103) [31], Lactobacillus casei LB31 [32], Lactococcus lactis ssp. lactis CNRZ 371 [33], Streptococcus thermophilus EU20 [34] and Streptococcus thermophilus RD534 [35], respectively and measured their interactions with $\beta$ lactoglobulin (BLG) using small-angle X-ray scattering (SAXS), dynamic light scattering (DLS) and analytical ultracentrifugation (AUC). These methods are well developed and have previously been used to examine solution structures of HePSs [36], structural evolution of metastable protein aggregates [37], heat- and salt-induced aggregation of BLG [38,39], as well as zinc- and polyanion-induced selfassociation of complement factor $\mathrm{H}[40,41]$. The present data provide novel information on associative interactions between a collection of structure-determined HePSs and BLG.

\section{Materials and methods}

\subsection{Production, purification and quantification of HePSs}


HePS-1, HePS-2 and HePS-5 were produced in 10\% skimmed milk medium by Lactobacillus delbrueckii ssp. bulgaricus NCIMB 702483 (NCIMB, Aberdeen, Scotland, United Kingdom), Lactobacillus rhamnosus GG (ATCC 53103) (ATCC, Manassas, VA, USA) and Streptococcus thermophilus EU20 (kind gift of Prof. Luc De Vuyst, Vrije Universiteit Brussels, Belgium), respectively, and were purified from the culture medium as we have described previously [36].

HePS-3 was produced in basal minimum medium (BMM) by Lactobacillus casei LB31 (kind gift of Dr. C. P. Champagne, Saint-Hyacinthe RDC, AAFC, Saint-Hyacinthe, QC, Canada) and was purified as described previously [42] with some modifications. Briefly, BMM containing glucose and lactose as carbon sources, was inoculated at an $\mathrm{OD}_{600}$ of 0.05 , and the culture was grown in a fermentor under constant stirring at $150 \mathrm{rpm}$ without aeration. The $\mathrm{pH}$ was controlled at 6.0 by $7 \mathrm{~N} \mathrm{NH}_{4} \mathrm{OH}$. To inactivate enzymes, the culture was heated in the fermentor at $90^{\circ} \mathrm{C}$ for 15 min under stirring, and after cooling, the cells were removed by centrifugation. If necessary, the supernatant was filtered under vacuum (Whatman \#41 filter; Fisher Scientific, Ottawa, ON, Canada). After concentrating the solution (Amicon DC10L ultrafiltration system equipped with a Romicon PM100 membrane cartridge; Qualtech, Saint-Hyacinthe, QC, Canada), the HePS was precipitated by three volumes of ethanol at $4^{\circ} \mathrm{C}$ overnight. The pellet collected by centrifugation was dissolved in deionized water, dialyzed and freeze-dried. Trichloroacetic acid (TCA, 10\% (w/v)) was added to the freeze-dried powder to precipitate proteins. After centrifugation $(15,800 \mathrm{~g}$ at room temperature), the supernatant was dialyzed, filtered if necessary (Millipore Express Plus $0.22-\mu \mathrm{m}$ filter; Fisher Scientific) under vacuum and freeze-dried.

HePS-4 was produced by Lactococcus lactis ssp. lactis CNRZ 371 obtained from INRA (Rennes, France) culture collection grown in $10 \%$ skimmed milk, inoculated at an $\mathrm{OD}_{600}$ of 0.05 for $24 \mathrm{~h}$ at $30^{\circ} \mathrm{C}$ under aerobic conditions without stirring. After homogenization of the culture by vigorous agitation 
followed by enzyme inactivation as described above, cells and proteins were removed by stirring with TCA (final concentration $20 \%(\mathrm{w} / \mathrm{v})$ ) for $20 \mathrm{~min}$ at R.T. After centrifugation and filtration (if necessary), crude HePS was precipitated with one volume of acetone at $4^{\circ} \mathrm{C}$ overnight, centrifuged, dissolved in deionized water, and the solution was extracted twice with one volume of phenol/chloroform/isoamyl alcohol 25:24:1 and once with one volume of chloroform/isoamyl alcohol 24:1. After acetone precipitation and centrifugation as described above, the purified HePS was dissolved in deionized water, dialyzed, filtered (if necessary) and freeze-dried.

HePS-6 was produced by Streptococcus thermophilus RD534 obtained from Danisco [35]. Isolation of HePS-6 was done as for HePS-3 followed by gel filtration (Sephacryl S-400, XK26-100 column; GE Healthcare, Uppsala, Sweden). Elution was performed with $50 \mathrm{mM} \mathrm{NH} \mathrm{HCO}_{3}$ at a flow rate of 1.3 $\mathrm{ml} / \mathrm{min}$ (Knauer Smartline system equipped with a differential refractometer model RI 2300 and an ultraviolet detector model 2600; Knauer, Berlin, Germany). Fractions corresponding to a positive refractive index peak with no absorption at 280 and $254 \mathrm{~nm}$ were pooled and freeze dried.

HePS was quantified using the phenol-sulfuric acid method and monosaccharide mixtures corresponding to the composition of the various repeat units as standards [43].

\subsection{Sample preparation}

BLG (6 mg/ml) was dissolved in milliQ water by stirring (150 rpm, overnight, R.T.). The solution was centrifuged $\left(12,000 \mathrm{~g}, 20 \mathrm{~min}, 20^{\circ} \mathrm{C}\right)$, filtered $(0.22 \mu \mathrm{m}$ syringe filter; Frisenette ApS, Knebel, Denmark) and the concentration was measured at $280 \mathrm{~nm}$ using a molar extinction coefficient $\varepsilon=$ $17,600 \mathrm{M}^{-1} \cdot \mathrm{cm}^{-1}[44]$. HePSs $(2-3 \mathrm{mg} / \mathrm{ml})$ were dissolved in milliQ water by stirring (150 rpm, overnight, R.T.) to ensure complete hydration and filtered (0.45 $\mu \mathrm{m}$ syringe filter; Frisenette ApS). BLG and HePS stock solutions were diluted with buffers (stock $50 \mathrm{mM}$, final $10 \mathrm{mM}$ ), glycine (pH 2), 
sodium citrate/citric acid ( $\mathrm{pH} 3-6)$ and Tris- $\mathrm{HCl}(\mathrm{pH} 7-8)$, and mixed to the desired ratios. All solution mixtures were equilibrated for 2-3 min before analysis.

\subsection{Molecular weight $\left(M_{\mathrm{w}}\right)$ distribution determination}

Molecular weights of HePS-1-HePS-6 were determined by size-exclusion chromatography (SEC) as described [36], using a solvent delivery system (LC-10AD), autosampler (SIL-10A), RI detector (RID10A; all Shimadzu, Kyoto, Japan) and a size-exclusion column (Shodex OH-PK SB-805 HQ $300 \times 8$ mm, Showa Denko, Tokyo, Japan). Dextran standards of $M_{\mathrm{w}} 4.5 \mathrm{MDa}, 1.45 \mathrm{MDa}, 560 \mathrm{kDa}, 350 \mathrm{kDa}$ (American Polymer Standards Corporation, Mentor, OH, USA), 276.5 kDa, 196.3 kDa, 123 kDa, 43 kDa (Pharmacosmos, Holbaek, Denmark), and pullulan of $22 \mathrm{kDa}$ were used for calibration. Standards $(1-2.7 \mathrm{mg} / \mathrm{ml})$ and HePSs $(1-2 \mathrm{mg} / \mathrm{ml})$ were dissolved in mobile phase $(10 \mathrm{mM}$ sodium citrate/citric acid $\mathrm{pH} 4.0)$, degassed, kept overnight, filtered (0.45 $\mu \mathrm{m}$ filters; Frisenette ApS, Knebel, Denmark), and $100 \mu \mathrm{l}$ of the solution was subjected to SEC at a flow rate of $0.5 \mathrm{ml} / \mathrm{min}$. The SEC data were analyzed by TriSEC conventional GPC software.

\subsection{SAXS of BLG mixed with HePS-1-HePS-6}

SAXS experiments of BLG mixtures with HePS-1, HePS-2, HePS-3, HePS-4 and HePS-6 were performed on beamline BM29 at the European Synchrotron Radiation Facility (Grenoble, France) [45]. Samples were measured in 10 time frames using $2 \mathrm{~s}$ exposure time. SAXS data for mixtures of BLG with HePS-5 were collected at beamline I911-4 at the MAX IV (synchrotron radiation facility, Lund, Sweden) [46] using $20 \mathrm{~s}$ exposure time in eight time frames. These exposure times were optimized using on-line checks during acquisitions to avoid radiation damage effects. The sample size was approximately $40 \mu \mathrm{l}$ using an automated flow cell. Buffers were measured before and after each sample and averaged prior to subtraction. The frames were averaged to maximize signal-to-noise ratios. Buffer averaging and subtraction prior to data analysis was done in the PRIMUS program [47]. Data were 
collected for BLG at $1 \mathrm{mg} / \mathrm{ml}$ and its mixtures with HePS-1-HePS-5 at 50, 100 and $150 \mu \mathrm{g} / \mathrm{ml}$, and with HePS-6 at 100 and $150 \mu \mathrm{g} / \mathrm{ml}$ in $10 \mathrm{mM}$ sodium citrate $\mathrm{pH} 4.0$. Guinier analysis gives the radius of gyration $R_{\mathrm{G}}$ that monitors the degree of structural elongation in solution if the internal inhomogeneity of scattering within the macromolecules has no effect. Guinier plots at low $Q$ (where $Q$ $=4 \pi \sin \theta / \lambda ; 2 \theta$ is the scattering angle and $\lambda$ is the wavelength) give $R_{\mathrm{G}}$ and the forward scattering at zero angle $I(0)[48]$ :

$$
\ln I(Q)=\ln I(0)-R_{\mathrm{G}}^{2} Q^{2} / 3
$$

The $R_{\mathrm{G}}$ analysis was done using PRIMUS. Indirect Fourier transformation of the full scattering curve $I(Q)$ measured in reciprocal space into real space gives the distance distribution function $P(r) . P(r)$ represents the distribution of distances $r$ between volume elements and gives an alternative calculation of $R_{\mathrm{G}}$, the maximum dimension $L$ of the macromolecule and the most commonly occurring distance $M$ within the macromolecule.

$$
P(r)=\frac{1}{2 \pi^{2}} \int_{0}^{\infty} I(Q) Q r \sin (Q r) d Q
$$

The transformation was carried out using the GNOM software [49].

\subsection{DLS of BLG mixed with HePS-1-HePS-6}

Size distribution experiments for BLG mixtures with HePS-1-HePS-6 were performed in $10 \mathrm{mM}$ glycine $\mathrm{pH} 2$, sodium citrate $\mathrm{pH}$ 3-6 and Tris- $\mathrm{HCl} \mathrm{pH}$ 7-9 buffers at a scattering angle of $90^{\circ}(\mathrm{BI}-$ 200SM instrument; Brookhaven Instruments Corporation; Holtsville, NY, USA) and $23^{\circ} \mathrm{C}$. DLS experiments for BLG mixed with HePS-1-HePS-6 in $10 \mathrm{mM}$ sodium citrate pH 4.0 were also performed at $23^{\circ} \mathrm{C}$ using a Malvern Zetasizer Nano ZS (Malvern Instruments, Worcestershire, United Kingdom) equipped for backscattering at $173^{\circ}$ with a $633 \mathrm{~nm} \mathrm{He}-\mathrm{Ne}$ laser. 
DLS studies the size distribution of particles undergoing Brownian motion through illumination by a laser beam. Time-dependent fluctuations in the intensity of scattered light reflect the rate at which the particles diffuse. The distributions of mean apparent translational diffusion coefficients $\left(D_{\mathrm{T}}\right)$ were determined by fitting the DLS autocorrelation functions obtained by the Brookhaven system using nonnegative constrained least-squares. The distribution of $D_{\mathrm{T}}$ values was converted to the distribution of hydrodynamic diameters ( $d_{\mathrm{H}}$, also known as Z-average) using the Stokes-Einstein equation:

$$
d_{\mathrm{H}}=k T / 3 \pi \eta D_{\mathrm{T}}
$$

where $k$ is the Boltzmann constant, $T$ the absolute temperature, and $\eta$ the solvent viscosity (assumed to be that of water, $0.933 \mathrm{mPa} \cdot \mathrm{s})$.

\subsection{Turbidity and protein measurements}

Turbidity (at $600 \mathrm{~nm}$ ) and protein absorbance (at $280 \mathrm{~nm}$ ) of BLG-HePS-1 and BLG-HePS-3 mixtures were measured using Ultrospec pro 2100 spectrophotometer (Amersham Biosciences, Cambridge, United Kingdom).

\subsection{AUC of BLG-HePS-2 mixtures}

AUC was run only for HePS-2 mixed with BLG, because only HePS-2 formed soluble aggregates (non-visible). Sedimentation velocity experiments for BLG and BLG-HePS-2 mixtures were performed using a Beckman XL-A analytical ultracentrifuge (Beckman Coulter, Inc., Palo Alto, CA, USA) equipped with absorbance optics. Experiments for BLG at $0.5 \mathrm{mg} / \mathrm{ml}$ and for BLG-HePS-2 mixtures at 50 and $100 \mu \mathrm{g} / \mathrm{ml} \mathrm{HePS}-2$ were done in $10 \mathrm{mM}$ sodium citrate $\mathrm{pH} 4.0$. Buffer density of $0.9988 \mathrm{~g} / \mathrm{ml}$ and partial specific volume of $0.74915 \mathrm{ml} / \mathrm{g}$ were calculated with SEDNTERP (version 1.09) [50]. Prior to the start of experiments, BLG-HePS-2 mixtures were centrifuged at 10,000 rpm for $10 \mathrm{~min}$ and filtered through $0.45 \mu \mathrm{m}$ filters to remove traces of larger insoluble aggregates. 
Sedimentation velocity data were collected at 50,000 rpm using a four-hole AnTi50 rotor with standard double-sector cells with column heights of $12 \mathrm{~mm}$ at $20^{\circ} \mathrm{C}$ using absorbance optics at $280 \mathrm{~nm}$. The continuous $c(s)$ analysis method was used to determine the sedimentation coefficients $s_{20, \mathrm{w}}$ of BLG and BLG-HePS-2 using the SEDFIT software (version 14.1) [51].

\section{Results and discussion}

\subsection{HePS repeat units and molecular weight $\left(M_{\mathrm{w}}\right)$ distribution}

HePS-1, HePS-2, HePS-3, HePS-4, HePS-5 and HePS-6 consist of repeat units of dp7 (where dp stands for degree of polymerization) composed of glucose, rhamnose and galactose (molar ratio of 1:1:5) [52], dp6 of $N$-acetyl-glucosamine, rhamnose and galactose (molar ratio of 1:1:4) [31], dp7 of glucose, rhamnose, galactose and pyruvate (molar ratio of 2:4:1:1) [42], dp7 of glucose, rhamnose and galactose (molar ratio of 2:2:3) [53], dp7 of glucose, rhamnose and galactose (molar ratio of 2:2:3) [33] and dp4 composed of glucose and galactose (molar ratio of 2:2) [54] (Fig. 1).

$M_{\mathrm{w}}$ was determined to be $372 \pm 8 \mathrm{kDa}$ for HePS-1, $389 \pm 6 \mathrm{kDa}$ for HePS-2, $134 \pm 10 \mathrm{kDa}$ for HePS3, $12477 \pm 1186 \mathrm{kDa}$ for HePS-4 and $385 \pm 10 \mathrm{kDa}$ for HePS-6 [25] and $145 \pm 4 \mathrm{kDa}$ for HePS-5 (Fig. S1) by SEC. HePS-4 eluted in the exclusion volume, however, its $M_{\mathrm{w}}$ was estimated by extrapolation of the linear calibration curve, although this likely leads to underestimation. It is important to note that the size of the HePSs represents the apparent $M_{\mathrm{w}}$, as dextrans and pullulan were used to establish the SEC calibration curves due to unavailability of comparable exopolysaccharides of known molar mass. The polydispersity values derived from SEC were 3.59 for HePS-1, 2.68 for HePS-2, 2.67 for HePS-3, 2.20 for HePS-5 and 2.65 for HePS-6. Because HePS-4 was eluted in the exclusion volume, the polydipersity was not calculated.

\subsection{SAXS of BLG mixed with HePS-1-HePS-6}

Association of BLG in the absence and presence of HePS-1-HePS-6 was studied by SAXS. The 
scattering data $I(Q)$ for BLG and its mixtures with HePSs showed excellent signal-to-noise ratios with no radiation damage.

\subsubsection{Guinier analyses}

The Guinier analyses of $\ln I(Q)$ versus $Q^{2}$ at low $Q$ values give the radius of gyration $R_{\mathrm{G}}$ that measures the degree of macromolecular elongation in solution. The Guinier fits of free BLG resulted in an $R_{\mathrm{G}}$ value of $2.49 \pm 0.10 \mathrm{~nm}$ using a $Q$ range of $0.21-0.48 \mathrm{~nm}^{-1}$ (Fig. S2), in good agreement with the $R_{\mathrm{G}}$ values of $2.16 \pm 0.04$ to $2.54 \pm 0.04 \mathrm{~nm}$ reported for the BLG dimer at various $\mathrm{pH}$ values $[55,56]$. The distance distribution function $P(r)$ of BLG gave an $R_{\mathrm{G}}$ value of $2.51 \pm$ $0.03 \mathrm{~nm}$ and maximum length $L$ of $7.9 \mathrm{~nm}$, suggesting that BLG exists as a dimer at $\mathrm{pH} 4.0$ (Table 1, Fig. S2, inset).

Scattering plots (log $I$ vs $Q$ ) of BLG mixed with HePS-1, HePS-2, HePS-3 and HePS-4 resulted in a significant upturn of the intensities at low $Q$ values shown by considerable deviation from linearity (Fig. 2). This deviation was most pronounced in the case of BLG-HePS-1, BLG-HePS-2 and BLG-HePS-3 mixtures. Such upturn of intensity at low $Q$ values is indicative of formation of relatively large aggregates [40,57] and therefore we did not perform Guinier analysis of these samples. No significant upturn in the intensities were observed for BLG-HePS-5 and HePS-6 mixtures (Fig. S3). 
Table 1. SAXS and DLS experimental data for BLG and its mixtures with HePSs

\begin{tabular}{|c|c|c|c|c|c|}
\hline & $\begin{array}{c}\text { Concentration } \\
\mathrm{mg} / \mathrm{ml}\end{array}$ & $\begin{array}{l}\text { Molecular } \\
\text { weight (kDa) }\end{array}$ & $R_{\mathrm{G}}(\mathrm{nm})^{\mathrm{a}}$ & $\begin{array}{l}\text { Length } L \\
(\mathrm{~nm})\end{array}$ & $d_{\mathrm{H}}(\mathrm{nm})$ \\
\hline BLG & 1.0 & 18.4 & $2.51 \pm 0.03$ & 7.9 & $8.5 \pm 1.2$ \\
\hline HePS-1 & 0.1 & $372 \pm 8$ & $13 \pm 0.3$ & 42 & $57 \pm 1$ \\
\hline \multirow[t]{3}{*}{ BLG+HePS-1 } & $1.0+0.05$ & & 39 & 114 & \\
\hline & $1.0+0.10$ & & 42 & 124 & $470 \pm 173$ \\
\hline & $1.0+0.15$ & & 43 & 129 & \\
\hline HePS-2 & 0.1 & $389 \pm 6$ & $13 \pm 0.3$ & 44 & $47 \pm 3$ \\
\hline \multirow[t]{3}{*}{ BLG+HePS-2 } & $1.0+0.05$ & & 20 & 65 & \\
\hline & $1.0+0.10$ & & 35 & & $397 \pm 7$ \\
\hline & $1.0+0.15$ & & 37 & 102 & \\
\hline HePS-3 & 0.1 & $134 \pm 10$ & $10 \pm 1$ & 38 & $51 \pm 7$ \\
\hline \multirow[t]{3}{*}{ BLG+HePS-3 } & $1.0+0.05$ & & $22 \pm 1$ & 76 & \\
\hline & $1.0+0.10$ & & $37 \pm$ & 109 & $1457 \pm 49$ \\
\hline & $1.0+0.15$ & & 44 & 116 & \\
\hline HePS-4 & 0.4 & $12477+1186$ & $17 \pm 1$ & 68 & $87 \pm 2$ \\
\hline \multirow[t]{3}{*}{ BLG+HePS-4 } & $1.0+0.05$ & & & 68 & \\
\hline & $1.0+0.10$ & & 27 & 84 & $174 \pm 8$ \\
\hline & $1.0+0.15$ & & 30 & 87 & \\
\hline HePS-5 & 0.1 & $145 \pm 4$ & $12 \pm 0.3$ & 41 & $29 \pm 1$ \\
\hline \multirow[t]{3}{*}{ BLG+HePS-5 } & $1.0+0.05$ & & 4 & n.d. & \\
\hline & $1.0+0.10$ & & 6 & n.d. & $21 \pm 2$ \\
\hline & $1.0+0.15$ & & 7 & n.d. & \\
\hline HePS-6 & 0.1 & $385 \pm 10$ & $20 \pm 0.3$ & 70 & $56 \pm 1$ \\
\hline \multirow[t]{2}{*}{ BLG+HePS-6 } & $1.0+0.10$ & & $8 \pm 1$ & 35 & $33 \pm 3$ \\
\hline & $1.0+0.15$ & & 19 & 66 & \\
\hline
\end{tabular}

a: Derived from GNOM $P(r)$ analyses (STDEV $<1$ is not shown for all complexes); n.d.: not determined 


\subsubsection{Distance distribution $P(r)$ analyses}

The distance distribution function $P(r)$ provides information on the shapes of BLG-HePSs aggregates. The $P(r)$ curve gives $R_{\mathrm{G}}$ values as well as model-independent determinations of overall length $L$ and yields most frequently occurring distances $M$ from the position of peak maximum. Values of $L$ were measured from the $r$ value where the $P(r)$ curve becomes zero.

For BLG-HePS-1 mixture, two peaks (M1 and $M 2$ ) were observed at $r$ of 3-4 and $49-59 \mathrm{~nm}, R_{\mathrm{G}}$ of 39-43 $\mathrm{nm}$ and maximum length $L$ of 124-129 nm at 100 and $150 \mu \mathrm{g} / \mathrm{ml} \mathrm{HePS}-1$ (Fig. 3A, Fig. 4A, Table 1). These $R_{\mathrm{G}}$ and $L$ values were $\sim 3$-fold larger than the $R_{\mathrm{G}}$ of $12.9 \pm 0.3$ and $L$ of $42.0 \mathrm{~nm}$ measured for free HePS-1 (Table 1). The $M 1$ and $M 2$ values for free HePS-1 were 2 and $12 \mathrm{~nm}$. The $I(0) / c$ value is proportional to the relative molecular mass $[40,49,58]$ and increased greatly with increase in concentration of HePS-1 (Fig. 3B), showing large aggregate formation when BLG was mixed with HePS-1.

For BLG-HePS-2 mixtures, $P(r)$ analyses resulted in $R_{\mathrm{G}}$ values of $20-37 \mathrm{~nm}$ at 50,100 and 150 $\mu \mathrm{g} / \mathrm{ml}$ HePS-2 (Fig. 3A, Table 1). The maximum length $L$ of $100-102 \mathrm{~nm}$, and $M 1$ and $M 2$ at $r$ of 3-3 and 43-46 nm were observed at 100 and $150 \mu \mathrm{g} / \mathrm{ml} \mathrm{HePS}-2$ (Fig. 4B, Table 1). These values were larger than the $R_{\mathrm{G}}$ value of $13 \pm 0.3 \mathrm{~nm}, L$ of $44 \mathrm{~nm}$ and $M$ of $10 \mathrm{~nm}$ as measured for free HePS-2, indicating formation of large aggregates. The corresponding $I(0) / c$ values also increased significantly with increase in concentration of HePS-2 (Fig. 3B). These $R_{G}$ and $I(0) / c$ values for BLG-HePS-2 mixtures were smaller than those observed for BLG-HePS-1 mixtures, suggesting that these aggregates are smaller in size than aggregates with HePS-1. This difference may be explained by a lower degree of branching in HePS-2, although there are three $\alpha-1 \rightarrow 3$ linkages in the repeat unit 
backbone, which make HePS-2 more flexible to adopt a compact conformation in solution [36]. These data suggest that a high degree of branching may promote optimal binding with proteins.

The $P(r)$ analyses for BLG mixed with HePS-3 $(50,100$ and $150 \mu \mathrm{g} / \mathrm{ml})$ gave $R_{\mathrm{G}}$ values of $22-44$ nm (Fig. 3A, Table 1). Two peaks (M1 and $M 2)$ at $r$ of 2-3 and 48-56 nm, and maximum length $L$ of 109-116 nm were observed at both 100 and $150 \mu \mathrm{g} / \mathrm{ml} \mathrm{HePS}-3$ (Fig. 4C, Table 1). Like $P(r)$ analyses for BLG-HePS-1 and BLG-HePS-2 mixtures, these values were also larger than the $R_{\mathrm{G}}$ of $10 \pm 1 \mathrm{~nm}$, $M$ of $4 \mathrm{~nm}$ and $L$ of $38 \mathrm{~nm}$ measured for free HePS-3, suggesting that BLG forms large aggregates with HePS-3. The $I(0) / c$ values increased greatly with increasing concentration of HePS-3 (Fig. 3B). These $R_{\mathrm{G}}$ and $I(0) / c$ values were larger than the corresponding $R_{\mathrm{G}}$ values observed for BLG-HePS-2 mixtures, but slightly smaller than those observed for BLG-HePS-1 mixtures, suggesting that BLG interacts strongly with HePS-3 and forms large aggregates. These aggregates with HePS-3 were smaller in size than those with HePS-1 and larger than HePS-2 aggregates. Pyruvate has a $\mathrm{p} K_{\mathrm{a}}$ of $\sim 2.5[59,60]$ and BLG has an isoelectric point $(\mathrm{p} I)$ of $4.7-5.2$ [61,62]. Therefore, HePS-3 is anticipated to interact with $\mathrm{BLG}$ at $\mathrm{pH}<5$ through electrostatic interactions. Although direct evidence of electrostatic interactions between HePS pyruvate groups and BLG is not reported, studies using other anionic polysaccharides, e.g. alginate and carrageenan have shown strong interaction with $\mathrm{BLG}$ at $\mathrm{pH}<\mathrm{p} I$ and formation of large complexes through electrostatic interactions, which was also shown for whey proteins and negatively charged polysaccharides [61,63-65]. Compared to HePS-1 and HePS-2, HePS3 exhibited a less compact conformation, supposedly due to repulsion between pyruvate groups.

The $P(r)$ analyses for BLG mixed with HePS-4 $(50,100$ and $150 \mu \mathrm{g} / \mathrm{ml})$ resulted in $R_{\mathrm{G}}$ of $18-30$ nm (Fig. 3A, Table 1). Two peaks (M1 and $M 2$ ) were obtained at $r$ of 2-3 and 33-33 nm, and maximum length, $L$ of 84-87 $\mathrm{nm}$ at 100 and $150 \mu \mathrm{g} / \mathrm{ml} \mathrm{HePS}-4$ (Fig. 4D, Table 1). The corresponding $I(0) / c$ values increased significantly with increasing concentration of HePS-4 (Fig. 3B). These values 
were smaller than those observed for HePS-1, HePS-2 and HePS-3 mixed with BLG, but larger than the $R_{\mathrm{G}}$ of $17 \pm 1, M$ of $4 \mathrm{~nm}$ and $L$ of $68 \mathrm{~nm}$ measured for free HePS-4, indicating weak aggregation when BLG is mixed with HePS-4. The reason for these weak interactions and aggregation remains elusive, but could be due to the low degree of branching of HePS-4.

When HePS-5 was added to BLG, the $P(r)$ analyses resulted in $R_{\mathrm{G}}$ values from 4-7 nm at 50, 100 and $150 \mu \mathrm{g} / \mathrm{ml} \mathrm{HePS}-5$ ( Fig. 3A, Table 1). These $R_{\mathrm{G}}$ values were smaller than the $R_{\mathrm{G}}$ of $12 \pm 0.3 \mathrm{~nm}$ of free HePS-5, indicating that no significant aggregation is observed. Similarly, the $P(r)$ analyses of BLG with HePS-6 gave $R_{\mathrm{G}}$ values of 8-19 nm at 100 and $150 \mu \mathrm{g} / \mathrm{ml}$, respectively (Fig. 3A, Table 1). These $R_{G}$ values remained in a similar range as observed for free HePS-6, suggesting that no significant aggregation is observed when HePS-6 is added.

In summary, $R_{\mathrm{G}}$ and $I(0) / c$ values increased greatly with increase in HePSs concentration, showing that BLG formed large aggregates with HePS-1-HePS-4. Moreover, the intensity of M1 corresponding to BLG peak maximum decreased with increasing HePS concentration, whereas M2 became more prominent, indicating an increase in aggregate formation (Fig. 4).

\subsection{DLS of BLG-HePS mixtures}

SAXS does not provide accurate structural information on very large BLG-HePS aggregates observed in the present study, since information at very low $Q$ range is hidden behind the beam stop. Thus, DLS which is sensitive to large aggregates, was used. The sizes of BLG mixed with HePS1-HePS-6 as a function of $\mathrm{pH}$ were analyzed using particle sizing software. Free BLG gave hydrodynamic diameter $d_{\mathrm{H}}$ (also called Z-average) of $6.0 \pm 0.3 \mathrm{~nm}$ at $\mathrm{pH} 2-3$ and $6.9 \pm 0.6 \mathrm{~nm}$ at $\mathrm{pH}$ 5-8. At $\mathrm{pH} 4.0$, the $d_{\mathrm{H}}$ of $8.5 \pm 1.2 \mathrm{~nm}$ for BLG agreed well with the SAXS length $L$ of $7.9 \mathrm{~nm}$ observed at $\mathrm{pH} 4.0$, in good agreement with the SAXS maximum dimension of 6-7 nm reported for the 
BLG dimer [66]. It has been reported that BLG exists as monomer at $\mathrm{pH} 2-3$ in salt-free conditions $[66,67]$.

For BLG mixed with HePS-1, $d_{\mathrm{H}}$ varied from $15.0 \pm 2$ to $39.0 \pm 6 \mathrm{~nm}$ when the $\mathrm{pH}$ decreased from 8.0 to 5.0 (Fig. 5). The $d_{\mathrm{H}}$ of BLG-HePS-1 mixtures increased dramatically to $2470 \pm 173 \mathrm{~nm}$ at $\mathrm{pH}$ 4.0, suggesting formation of large aggregates (Fig. 5, Table 1). Compared to $d_{\mathrm{H}}$ values at pH 4.0, a 2-7fold decrease in $d_{\mathrm{H}}$ was seen when the $\mathrm{pH}$ decreased from 3.0 to 2.0 (Fig. 5). This suggests that: i) dimeric BLG forms large aggregates by providing more optimal surface contacts with HePSs compared to the monomeric form; ii) because $\mathrm{pH} 4$ is closer to the $\mathrm{p} I$ of $\mathrm{BLG}$, the complexes are additionally more stabilized by hydrophobic interactions compared to $\mathrm{pH} 2-3$. Since large aggregates were observed, DLS experiments for BLG-HePS-1 mixtures were further performed at a backscattering angle of $173^{\circ}$ at $\mathrm{pH} 4.0$. Backscattering resulted in a $d_{\mathrm{H}}$ of $1732 \pm 58 \mathrm{~nm}$ for BLG-HePS-1 mixtures and a $d_{\mathrm{H}}$ of $57 \pm 1 \mathrm{~nm}$ for free HePS-1. The data (both at $90^{\circ}$ and $173^{\circ}$ ) showed that large aggregates were formed at $\mathrm{pH} 4.0$, thus supporting the SAXS data.

Similarly, a large increase in $d_{\mathrm{H}}$ was observed when HePS-2 and HePS-3 were added to BLG solution at $\mathrm{pH}<5$, resulting in $d_{\mathrm{H}}$ of $397 \pm 7$ and $1457 \pm 49 \mathrm{~nm}$ for BLG-HePS-2 and BLG-HePS-3 mixtures at $\mathrm{pH}$ 4.0, respectively (Fig. 5, Table 1). Like for the BLG-HePS-1 mixture, a decrease in size was found by decreasing $\mathrm{pH}$ from 3.0 to 2.0 (Fig. 5). At $173^{\circ}$, DLS experiments of BLG mixed with HePS-2 and HePS-3 at pH 4.0 gave $d_{\mathrm{H}}$ of $279 \pm 27$ and $444 \pm 51 \mathrm{~nm}$, respectively. These values were much larger than $d_{\mathrm{H}}$ of $47 \pm 3$ and $51 \pm 7 \mathrm{~nm}$ observed at $173^{\circ}$ for free HePS-2 and HePS-3, respectively, at $\mathrm{pH}$ 4.0. Furthermore, DLS analyses of BLG-HePS-2 at $173^{\circ}$ showed that the size increased with time, suggesting that the complexes initially formed associate to form larger entities (Fig. S4).

Compared to the above DLS results, only a small increase in the $d_{\mathrm{H}}$ of BLG mixed with HePS-4 was observed at $\mathrm{pH}<5$. For BLG-HePS-4 mixtures, $d_{\mathrm{H}}$ of $79 \pm 11-174 \pm 8 \mathrm{~nm}$ at $\mathrm{pH} 2.0-4.0$ and $12.8 \pm$ 
$3.2 \mathrm{~nm}$ were observed at $\mathrm{pH}$ 6. DLS of BLG-HePS-4 at $173^{\circ}$ gave $d_{\mathrm{H}}$ of $99 \pm 0.7 \mathrm{~nm}$ at $\mathrm{pH} 4.0$, larger than the $d_{\mathrm{H}}$ of $87 \pm 2 \mathrm{~nm}$ observed for free HePS-4 at pH 4.0, indicating that HePS-4 interacts with BLG at $\mathrm{pH}<5$ (Fig. 5). Like SAXS data for BLG mixed with HePS-5 and HePS-6, no significant changes were observed in the size distribution analyses, suggesting that no significant interactions occur between these HePSs and BLG (data not shown).

In summary, the DLS size distribution analyses showed that larger aggregates were formed with HePS-1, HePS-2, HePS-3 and HePS-4, whereas no significant effects were observed when HePS-5 and HePS-6 were added to BLG. For the BLG-HePS-1, BLG-HePS-2 and BLG-HePS-3 samples the $d_{\mathrm{H}}$ values derived from DLS data were significantly larger than the maximum length $L$ observed in SAXS data. The difference in size of these large aggregates is attributed to the lack of structural information from the SAXS data at the very low $Q$ values hidden behind the beam stop. Therefore, the result obtained from $P(r)$ analyses is qualitative, not quantitative.

\subsection{Turbidity and protein absorbance of BLG-HePS mixtures}

Turbidity and protein absorbance measurements from the DLS samples (Fig. 5) were performed in order to assess the solubility of the complexes. Turbidity was observed only in the case of HePS-1 and HePS-3 when mixed with BLG, whereas no turbidity was observed with BLG-HePS-2 and HePS-4 mixtures, consistent with the much smaller values of $d_{\mathrm{H}}$ reported for these mixtures. In both experiments, a turbidity increase was observed at $\mathrm{pH}<5$, whereas no change was observed at $\mathrm{pH}>5$, suggesting attractive interactions (usually assumed to be electrostatic, van der Waals and hydrophobic interactions, and hydrogen bonding) between BLG and HePSs (Fig. 6). Mixing polysaccharides with proteins can result in two types of phase separation: repulsive phase separation (thermodynamic incompatibility) that occurs at high concentrations of neutral or similarly charged protein and polysaccharide, and attractive phase separation (thermodynamic compatibility) that occurs between 
molecules that carry opposite charges or polarity [68]. Here, we suggest that there could be an associative phase separation when mixing BLG with HePSs. A significant decrease in turbidity was observed at $\mathrm{pH} 2.0$, indicative of dissociation of large complexes. This increase in turbidity at $\mathrm{pH}<5$ was supported by a decrease in protein absorbance at $280 \mathrm{~nm}$ in solution after centrifugation. A decrease in protein concentration in solution at $\mathrm{pH}<5$ reflected formation of insoluble BLG-HePS-1 and BLG-HePS-3 complexes.

\subsection{AUC of BLG-HePS-2 soluble complexes}

AUC was used as a comparative method for analysis of soluble complexes of BLG-HePS-2. The sedimentation coefficient $s_{20, \mathrm{w}}$ monitors macromolecular elongation as well as associative and polydispersity effects in solution. The absorbance analyses for free BLG resulted in a single peak with $s_{20, \mathrm{w}}$ of $2.71 \pm 0.03 \mathrm{~S}$ which corresponds to a molecular mass of $33.3 \pm 1.0 \mathrm{kDa}$ obtained from the $c(M)$ plot, attributed to the BLG homodimer (Fig. 7). The absorbance analyses of BLG-HePS-2 gave one major peak with $s_{20, \mathrm{w}}$ of $2.74 \pm 0.21 \mathrm{~S}$ attributed to free BLG and one small peak with $s_{20, \mathrm{w}}$ of $27.56 \pm$ $0.21 \mathrm{~S}$ which correspond to a large BLG-HePS-2 soluble complex (Fig. 7) with molecular mass of around $1250 \pm 140 \mathrm{kDa}$ as indicated from the $c(M)$ plot. It is important to note that AUC cannot accurately measure large insoluble aggregates, because these aggregates tend to sediment faster before data collection at high centrifugal force.

The amounts of non-aggregated BLG and HePS-2-bound BLG were quantified using the integration function in the $c(s)$ analyses [69]. Integration of the non-aggregated BLG peak and the complex (bound) peak intensities in the $c(s)$ analyses permitted estimation of non-aggregated BLG and bound BLG in the BLG-HePS-2 mixture. Based on the comparison with free BLG, integration of nonaggregated BLG and bound BLG peak in the BLG-HePS-2 mixture showed that the amount of nonaggregated BLG was $93 \%$ and $88 \%$ and of bound BLG was 4.6 and $9.8 \%$ at 50 and $100 \mu \mathrm{g} / \mathrm{ml} \mathrm{HePS}-2$, 
respectively. The amount of insoluble BLG removed by centrifugation/filtration was estimated to 1.6-2.2\% based on comparison with free BLG. Sedimentation velocity experiment for BLG-HePS-1 mixtures was also performed for analysis of soluble BLG-HePS-1 complex. However, no significant signal for soluble BLG-HePS-1 complex was observed (Fig. S5), indicating that insoluble aggregates were formed which was in agreement with turbidity assay (Fig. 6).

Previously, we have reported that LAB HePSs exhibited compact conformation in solution as determined by SAXS and DLS in conjunction with scattering modeling [63]. The types of glycosidic linkage in the backbone, the presence of side groups and the branched structure all play an important role in technological functionality of bacterial EPSs $[20,70]$. It have been reported that partial removal of the side groups in the repeating units of LAB HePSs tends to reduce the chain stiffness [70]. Since LAB EPSs are structurally very diverse, understanding the extent and nature of HePS-protein interactions is highly challenging. From our present results, we propose that the associative interactions between BLG and HePS-1-HePS-6 can be explained mainly by the degree of branching and presence of more flexible glycosidic linkages such as $\alpha-1 \rightarrow 2, \alpha-1 \rightarrow 3$ and $\alpha-1 \rightarrow 4$ linkages in the backbone. Compared to the stiffer $\beta-1 \rightarrow 4$ linkages, the presence of these linkages in the backbone confers enough flexibility to HePSs to bring and spatially arrange distant side groups in close proximity for optimal binding with proteins. For instance, the associative interactions between BLG and HePS-1 can be attributed to the presence of $\alpha-1 \rightarrow 2$ and $\alpha-1 \rightarrow 3$ linkages in the repeating units and the degree of branching involving $\alpha-1 \rightarrow 3, \beta-1 \rightarrow 3$ and $\beta-1 \rightarrow 4$ linkages, conferring semi-flexible behavior to HePS-1, allowing to adopt a local helical-like structure with a cluster of branches on one side of the backbone, with a similar cluster forming on the other side of the backbone. Thus HePS-1 structure has a compact conformation [36] that is preformed for optimal binding with proteins. Similarly, the results of the present study also showed that BLG aggregated strongly with the HePS containing a high degree of 
branching in its repeat unit compared to the ones with lower degree of branching, implying that a high degree of branching might play an important role in the associative interaction and aggregation by providing more optimal contacts with BLG. The interaction of BLG with HePSs appeared to be essentially independent of molecular weight of intact HePSs. For instance, the molecular weight of HePS-6 was in a similar range as that of HePS-1 and HePS-2, but HePS-6 has an extended conformation, and hence no significant effects were observed when HePS-6 was added to BLG solution. Similarly, for HePS-4 that has a very high $M_{\mathrm{w}}$ in comparison to HePS-1 and HePS-2 (Table 1), only weak aggregation was observed when HePS-4 was mixed with BLG as shown by SAXS and DLS.

\section{Conclusions}

In the present study, the interactions of six structurally different LAB HePSs (HePS-1-HePS-6) with BLG were investigated using SAXS, DLS and AUC. Both SAXS and DLS data analyses of BLG binding with HePS-1-HePS-6 at pH 4 revealed that BLG aggregated strongly with HePS-1, HePS-2 and HePS-3, weakly with HePS-4, and not with HePS-5 and HePS-6. BLG is negatively charged at $\mathrm{pH}>5$, and while DLS at $\mathrm{pH}$ 6.0-8.0 showed no significant interactions between HePS-1-HePS -4 and BLG, at $\mathrm{pH} 4.0$ both SAXS and DLS showed $R_{\mathrm{G}}$, maximum length $L$ and $d_{\mathrm{H}}$ values to increase dramatically, indicating formation of large aggregates. We conclude that the extent of aggregation depends on the compact conformation and degree of branching of the HePSs and that the interaction of BLG with the HePSs is essentially independent of the molecular weight of HePSs. Adding HePSs to BLG at $\mathrm{pH}<5$ resulted in formation of insoluble and soluble complexes as shown by turbidity and AUC analyses.

Although protein-polysaccharide complexes are reported to have diverse commercial applications in the food, biotechnology, medical, personal care and pharmaceutical industries $[61,71,72]$, the 
interactions between protein and polysaccharides are poorly understood. We propose that BLG molecules bind to LAB HePSs mainly through polar interactions resulting in formation of soluble and insoluble complexes. Structural studies using crystallographic and NMR techniques are underway in our group to identify the BLG residues involved in HePS binding. The present findings can be complemented by future dairy manufacture relevant analyses on rheological properties of these HePSs in mixtures with BLG and other whey proteins, and on particle morphology, structure and stability of BLG-HePS complexes by microscopy.

\section{Acknowledgements}

We thank Karina Jansen and Lotte Nielsen for their valuable technical assistance. This project was funded by the Danish Research Council for Independent Research | Technical and Production Sciences to the project "HEXPIN. Associative interactions between exopolysaccharides from lactic acid bacteria and milk proteins. Gaining insights deployable in design and optimised food texture". We also thank Prof. Luc de Vuyst, Vrije Universiteit of Brussel, Belgium, for providing the Streptococcus thermophilus EU20 strain. The ESRF, EMBL Hamburg and MAXIV synchrotrons are thanked for beam time and outstanding support during data collection. We would like to thank the Biophysics Facility from the Center for Protein Research, University of Copenhagen for granting us access to the AUC instrument. The research presented has received funding from BioStruct-X and DANSCATT (the Danish agency for Science, Technology and Innovation).

\section{References}

[1] F. Donot, A. Fontana, J.C. Baccou, S. Schorr-Galindo, Carbohydr. Polym. 87 (2012) 951-962.

[2] S.V. Dilna, H. Surya, R.G. Aswathy, K.K. Varsha, D.N. Sakthikumar, A. Pandey, K.M. 
Nampoothiri, LWT- Food Sci. Technol. 64 (2015) 1179-1186.

[3] M. Moscovici, Front. Microbiol. 6 (2015) 1012.

[4] S. Badel, T. Bernardi, P. Michaud, Biotechnol. Adv. 29 (2011) 54-66.

[5] E. Dertli, I.J. Colquhoun, A.P. Gunning, R.J. Bongaerts, G. Le Gall, B.B. Bonev, M.J. Mayer, A. Narbad, J. Biol. Chem. 288 (2013) 31938-31951.

[6] M.I. Torino, G. Font de Valdez, F. Mozzi, Front. Microbiol. 6 (2015) 834.

[7] S. Mende, M. Peter, K. Bartels, H. Rohm, D. Jaros, Food Hydrocoll. 32 (2013) 178-118.

[8] A. Laws, Y. Gu, V. Marshall, Biotechnol. Adv. 19 (2001) 597-625.

[9] N. Salazar, M. Gueimonde, C.G. de Los Reyes-Gavilán, P. Ruas-Madiedo, Crit. Rev. Food Sci. Nutr. 56 (2016) 1440-1453.

[10] J. Schmid, V. Sieber, B. Rehm, Front. Microbiol. 6 (2015) 1-24.

[11] S. Górska-Frączek, C. Sandström, L. Kenne, J. Rybka, M. Strus, P. Heczko, A. Gamian, Carbohydr. Res. 346 (2011) 2926-2932.

[12] P. Ruas-Madiedo, C.G. de los Reyes-Gavilán, J. Dairy Sci. 88 (2005) 843-856.

[13] L. De Vuyst, B. Degeest, FEMS Microbiol. Rev. 23 (1999) 153-177.

[14] A. Patel, J.B. Prajapati, Adv. Dairy Res. 1 (2013) 2.

[15] E.J. Faber, P. Zoon, J.P. Kamerling, J.F.G. Vliegenthart, Carbohydr. Res. 310 (1998) 269-276.

[16] R. Tuinier, E. Ten Grotenhuis, C. Holt, P.A. Timmins, C.G. De Kruif, Phys. Rev. E 60 (1999) 848-856.

[17] M. Girard, C. Schaffer-Lequart, Int. Dairy J. 17 (2007) 666-673.

[18] M-C. Gentès, D. St-Gelais, S. L. Turgeon, Dairy Sci. Technol. 91 (2011) 645-661

[19] Y.L. Doleyres, L. Schaub, C. Lacroix, J. Dairy Sci. 88 (2005) 4146-4156.

[20] P. Ruas-Madiedo, R. Tuinier, M. Kanning, P. Zoon, Int. Dairy J. 12 (2002) 689-695. 
[21] D.M. Folkenberg, P. Dejmek, A. Skriver, R. Ipsen, J. Dairy Res. 73 (2006) 385-393.

[22] I. Ayala-Hernández, A. Hassan, H.D. Goff, R. Mira de Orduña, M. Corredig, Int. Dairy J. 18 (2008) 1109-1118.

[23] L.N. Babol, B. Svensson, R. Ipsen, Food Biophys. 6 (2011) 468-473.

[24] S.K. Diemer, B. Svensson, L.N. Babol, D. Cockburn, P. Grijpstra, L. Dijkhuizen, D.M. Folkenberg, C. Garrigues, R.H. Ipsen, Food Biophys. 7 (2012) 220-226.

[25] J. Birch, H.K. Harðarson, S. Khan, M.R. Van Calsteren, R. Ibsen, C. Garrigues, Almdal, K., M. Abou Hachem, B. Svensson, Carbohydr. Polym. 177 (2017) 406-414.

[26] G. Morris, S. Harding, Polysaccharides, microbial, in: M. Schaechter (Ed.), Encyclopedia of Microbiology, third ed., Elsevier, Amsterdam, 2009, pp. 482-494.

[27] C. Delbarre-Ladrat, C. Sinquin, L. Lebellenger, A. Zykwinska, S. Colliec-Jouault, Front. Chem. 2 (2014) 85 .

[28] F. Freitas, V.D. Alves, M.A.M. Reis,Trends Biotechnol. 29 (2011) 388-398.

[29] I. Finore, P. Di Donato, V. Mastascusa, B. Nicolaus, A. Poli, Mar. Drugs 12 (2014) 3005-3024.

[30] K.K.T. Goh, D.R. Haisman, H. Singh, Appl. Microbiol Biotechnol. 67 (2005) 202-208.

[31] C. Landersjö, Z. Yang, E. Huttunen, G. Widmalm, Biomacromolecules, 3 (2002) 880-884.

[32] C.P. Champagne, Y. Raymond, J.P. Simon, Appl. Microbiol. Biotechnol. 95 (2012) 745-756.

[33] J. Cerning, C. Bouillanne, M. Landon, M.J. Desmazeaud, Dairy Sci. 75 (1992) 692-699.

[34] V.M. Marshall, H. Dunn, M. Elvin, N. McLay, Y. Gu, A.P. Laws, Carbohydr. Res. 331 (2001) $413-422$.

[35] G. Robitaille, A. Tremblay, S. Moineau, D. St-Gelais, C. Vadeboncoeur, M.J. Britten, Dairy Sci. 92 (2009) 477-482.

[36] S. Khan, J. Birch, P. Harris, M.-R. Van Calsteren, R. Ipsen, G.H. Peters, B. Svensson, K. Almdal, 
Biomacromolecules 18 (2017) 747-756.

[37] A. Sauter, F. Zhang, N.K. Szekely, V. Pipich, M. Sztucki, F. Schreiber, J. Phys. Chem. B 120 (2016) 5564-5571

[38] M. Pouzot, T. Nicolai, R.W. Visschers, M. Weijers, Food Hydrocoll. 19 (2005) 231-238.

[39] K. Ako, T. Nicolai, D. Durand, Biomacromolecules 11 (2010) 864-871.

[40] R. Nan, S. Tetchner, E. Rodriguez, P.J. Pao, J. Gor, I. Lengyel, S.J.J. Perkins, J. Biol. Chem. 288 (2013) 19197-19210.

[41] S. Khan, R. Nan, J. Gor, B. Mulloy, S.J. Perkins, Biochem. J. 444 (2012) 417-428.

[42] M.-R. Van Calsteren, C. Pau-Roblot, A. Bégin, D. Roy, Biochem. J. 363 (2002) 7-17.

[43] M. DuBois, K.A. Gilles, J.K. Hamilton, P.A. Rebers, F. Smith, Anal. Chem. 28 (1956) 350-356.

[44] M. Collini, L. D’Alfonso, G. Baldini, Protein Sci. 10 (2000) 1968-1974.

[45] T. Narayanan, O. Diat, P. Bosecke, Nucl. Instrum. Methods Phys. Res. A 467-468 (2001) 10051009.

[46] A. Labrador, Y. Cerenius, C. Svensson, K. Theodor, T.J. Plivelic, Phys. Conference Series 425 (2013) 072019.

[47] M.V. Petoukhov, D. Franke, A.V. Shkumatov, G. Tria, A.G. Kikhney, M. Gajda, C. Gorba, H.D.T. Mertens, P.V. Konarev, D.I. Svergun, J. Appl. Crystallogr. 45 (2012) 342-350.

[48] O. Glatter, O. Kratky, Small-Angle X-ray Scattering. Academic Press, New York, 1982.

[49] A.V. Semenyuk, D.I.J. Svergun, Appl. Crystallogr. 24 (1991) 537-540.

[50] T.M. Laue, B.D. Shah, T. M. Ridgeway, S.L. Pelletier, Computer-aided interpretation of analytical sedimentation data for proteins. In Analytical Ultracentrifugation in Biochemistry and Polymer Science (S. E. Harding, A.J. Rowe, J.C. Horton, eds), Royal Society of Chemistry, Cambridge UK. 1992, pp. 90-125. 
[51] P. Schuck, Biophys. J. 78 (2000) 1606-1619.

[52] M. Gruter, B.R. Leeflang, J. Kuiper, J.P. Kamerling, J.F.G. Vliegenthart, Carbohydr. Res. 239 (1993) 209-226.

[53] W.H.M. van Casteren, C. Dijkema, H.A. Schols, G. Beldman, A.G.J. Voragen, Carbohydr. Res. 324 (2000) 170-181.

[54] J. Lemoine, F. Chirat, J.-M. Wieruszeski, G. Strecker, N. Favre, J.-R. Neeser, Appl. Environ. Microbiol. 63 (1997) 3512-3518.

[55] M. Gottschalk, K. Venu, B. Halle, Biophys. J. 84 (2003) 3941-3958.

[56] C. Moitzi, L. Donato, L. Schmitt Bovetto, G. Gillies, A. Stradner, Food Hydrocoll. 25 (2011) $1766-1774$.

[57] Z. Quan, K. Zhu, K.D. Knudsen, B. Nyström, R. Lund, Soft Matter 9 (2013) 10768-10778.

[58] S.J. Perkins, A.I. Okemefuna, A.N. Fernando, A. Bonner, H.E. Gilbert, P.B. Furtado, Methods Cell Biol. 84 (2008) 375-423.

[59] D. Pines, J. Ditkovich, T. Mukra, Y. Miller, P.M. Kiefer, S. Daschakraborty, J.T. Hynes, E. Pines, J. Phys. Chem. B. 10 (2016) 120.

[60] Dewick, P. M. Essentials of Organic Chemistry: For Students of Pharmacy, Medicinal Chemistry and Biological Chemistry; Wiley: Chichester, UK, 2006.

[61] S.M.H. Hosseini, Z. Emam-Djomeh, P. Sabatino, P. Van der Meeren, Food Hydrocoll. 50 (2015) 16-26.

[62] S.M.H. Hosseini, Z. Emam-Djomeh, S. H. Razavi, A.A. Moosavi-Movahedi, A.A. Saboury,, M. S. Atri, P. Van der Meeren, Food Hydrocoll. 32 (2013) 235-244.

[63] T. Harnsilawat, R. Pongsawatmanit, D.J. McClements, Food Hydrocoll. 20 (2006) 577-585.

[64] R. Baeza, C.C. Sanchez, A.M.R. Pilosof, J.M.R. Patino, Food Hydrocoll. 19 (2005) 239-248. 
[65] V.B. Galazka, D. Smith, D.A. Ledward, E. Dickinson, Food Chem. 64 (1999) 303-310.

[66] G. Baldini, S. Beretta, G. Chirico, H. Franz, E. Maccioni, P. Mariani, F. Spinozzi, Macromolecules 32 (1999) 6128-6138.

[67] K. Sakurai, M. Oobatake, Y. Goto, Protein Sci. 10 (2001) 2325-2335.

[68] J.-L. Doublier, C. Garnier, D. Renarda, C. Sanchezb, Curr. Opin. Colloid. Interface. Sci. 5 (2000) $202-214$.

[69] A. Balbo, P. Schuck, Analytical Ultracentrifugation in the Study of Protein Self-association and Heterogeneous Protein-Protein Interactions. Inc; E. Golemis, P.D. Adams, ProteinProtein Interactions. Cold Spring Habor Laboratory Press Cold Spring Habor New York, 2005, pp. 253-277.

[70] R. Tuinier, W.H.M. van Casteren, P.J. Looijesteijn, H.A. Schols, A.G.J. Voragen, P. Zoon, Biopolymers 59 (2001) 160-166.

[71] N. Ron, P. Zimet, J. Bargarum, Y.D. Livney, Int. Dairy J. 20 (2010) 686-693.

[72] A. Ye, Int. J. Food Sci. Technol. 43 (2008) 406-415.

\section{Figure legends}

Figure 1. Repeat unit structures of HePS-1-HePS-6. HePS-1 from Lactobacillus delbrueckii ssp. bulgaricus (NCIMB 702483), HePS-2 from Lactobacillus rhamnosus GG (ATCC 53103), HePS-3 from Lactobacillus casei LB31, HePS-4 from Lactococcus lactis ssp. lactis (CNRZ 371), HePS-5 from Streptococcus thermophilus EU20 and HePS-6 from Streptococcus thermophilus RD534.

Figure 2. Small-angle X-ray scattering intensities of BLG, HePS-1-HePS-4 and their mixtures in 10 $\mathrm{mM}$ sodium citrate $\mathrm{pH} 4.0$. Results are shown for BLG at $1 \mathrm{mg} / \mathrm{ml}$, each $\mathrm{HePS}$ at $100 \mu \mathrm{g} / \mathrm{ml}$, and 
mixtures of BLG $(1 \mathrm{mg} / \mathrm{ml})$ with each HePS $(50,100$ and $150 \mu \mathrm{g} / \mathrm{ml})$. The upturn of intensities at low $Q$ values indicates aggregation.

Figure 3. Summary of the $P(r)$ analyses for BLG mixed with six HePSs. BLG $(1 \mathrm{mg} / \mathrm{ml})$ was mixed with HePS-1-HePS-5 (50, 100 and $150 \mu \mathrm{g} / \mathrm{ml})$, and with HePS-6 (100 and $150 \mu \mathrm{g} / \mathrm{ml})$ in $10 \mathrm{mM}$ sodium citrate $\mathrm{pH}$ 4.0. (A-B) Dependence of the $R_{\mathrm{G}}$ and $I(0) / c$ values of BLG calculated from $P(r)$ curves on the concentration of HePS-1-HePS-6. The data representation in B is the same as given in A.

Figure 4. Distance distribution function $P(r)$ analyses of BLG and its mixtures with HePS-1-HePS-4. BLG $(1 \mathrm{mg} / \mathrm{ml})$ was studied in the presence of 100 and $150 \mu \mathrm{g} / \mathrm{ml}$ of each HePS in $10 \mathrm{mM}$ sodium citrate $\mathrm{pH}$ 4. The unnormalized $P(r)$ curves for BLG alone and with HePS-1-HePS-4 were calculated from the scattering curves. These unnormalized curves compare the intensities between different BLGHePS complexes. The most frequently occurring distance $M$ and the maximum length $L$ where visible within free BLG and in the complex are indicated.

Figure 5. DLS characterization of BLG and BLG-HePS mixtures. Hydrodynamic diameter $d_{\mathrm{H}}$ of BLG ( $1 \mathrm{mg} / \mathrm{ml})$ and its mixtures with HePS-1, HePS-2, HePS-3 and HePS-4 (100 $\mu \mathrm{g} / \mathrm{ml})$ were measured as a function of $\mathrm{pH}$.

Figure 6. Turbidity (at $600 \mathrm{~nm}$, open circles) and absorbance (at $280 \mathrm{~nm}$, filled circles) of BLG mixed with HePS-1 and HePS-3 as a function of pH. The results shown in (A) and (B) are for the BLG-HePS1 and BLG-HePS-3 mixtures, respectively, used in Fig. 5.

Figure 7. Analytical ultracentrifugation (AUC) size-distribution analyses $c(s)$ of BLG mixed with HePS-2. BLG $(0.5 \mathrm{mg} / \mathrm{ml})$ was studied in the presence of HePS-2 $(50$ and $100 \mu \mathrm{g} / \mathrm{ml})$ at a rotor speed of 50,000 rpm in $10 \mathrm{mM}$ sodium citrate $\mathrm{pH} 4.0$. The BLG dimer peak is labelled as 1 , and the BLGHePS-2 complex peak is labelled as 2. 
HePS-1

$\beta$-D-Galp

$\beta$-D-Galp
1
$\downarrow$
4

$\alpha$-L-Rhap

$\downarrow$

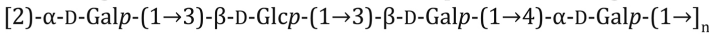

HePS-2 $\beta$-D-Galf

1

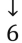

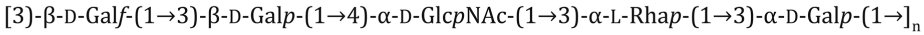

HePS-3

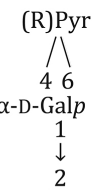

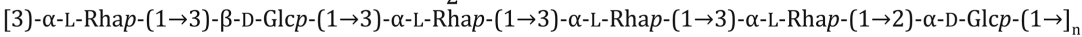

HePS-4

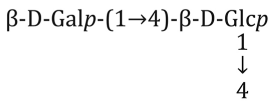

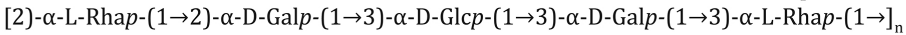

HePS-5

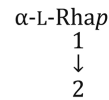

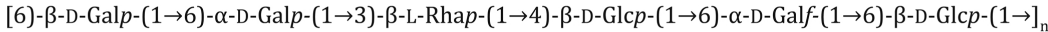

HePS-6

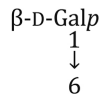

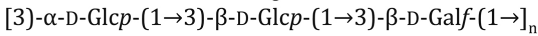

Figure 1 


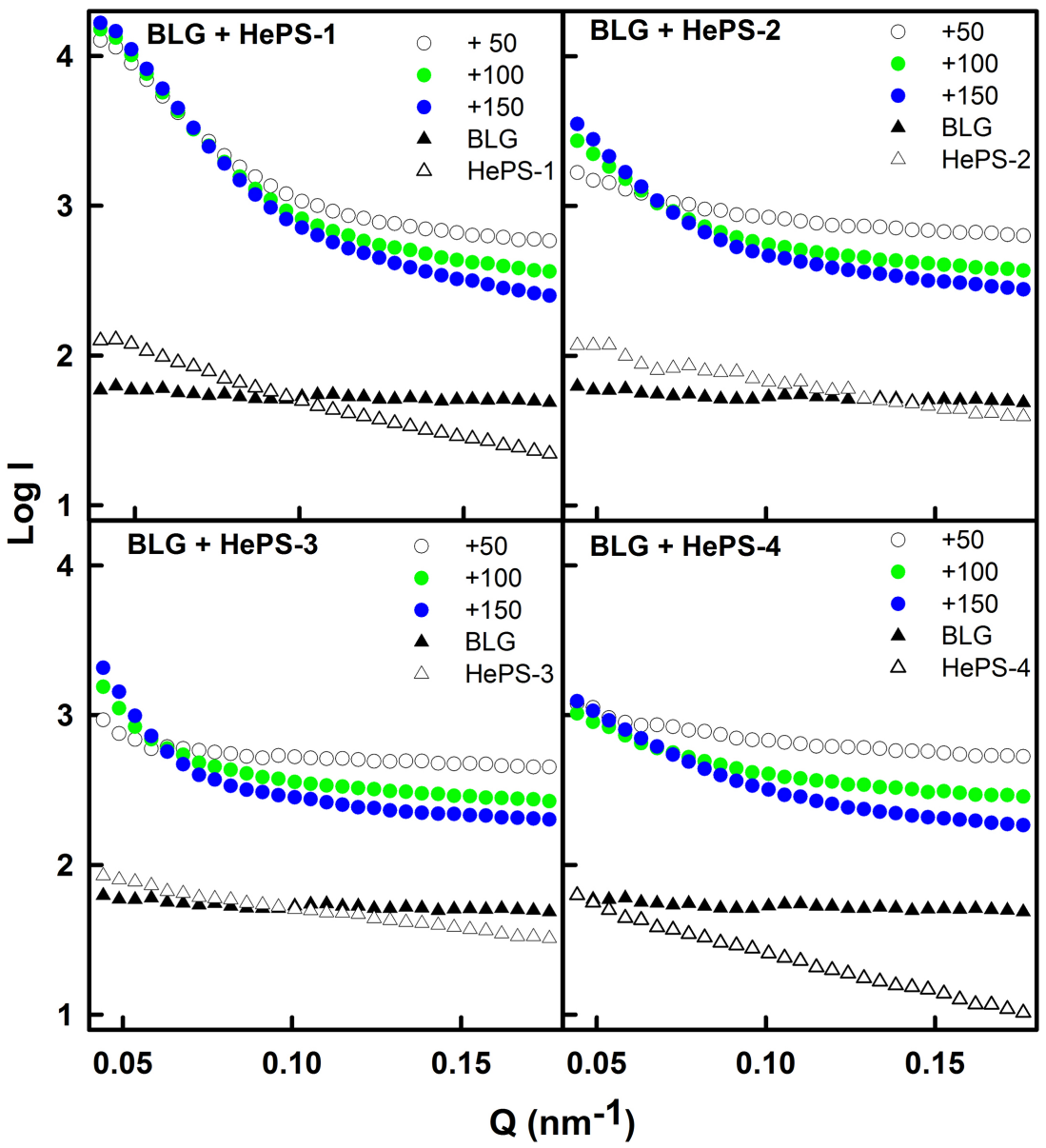

Figure 2 


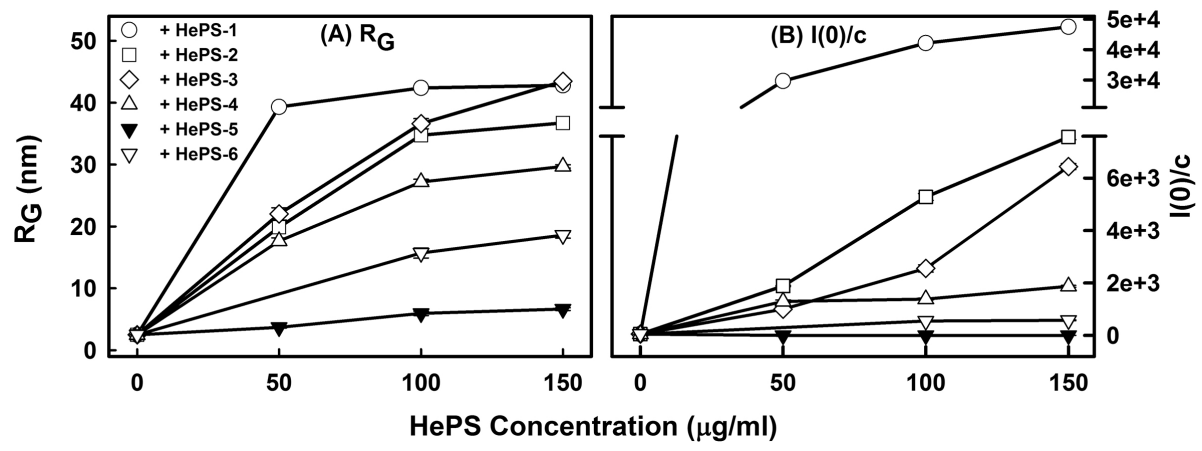

Figure 3 


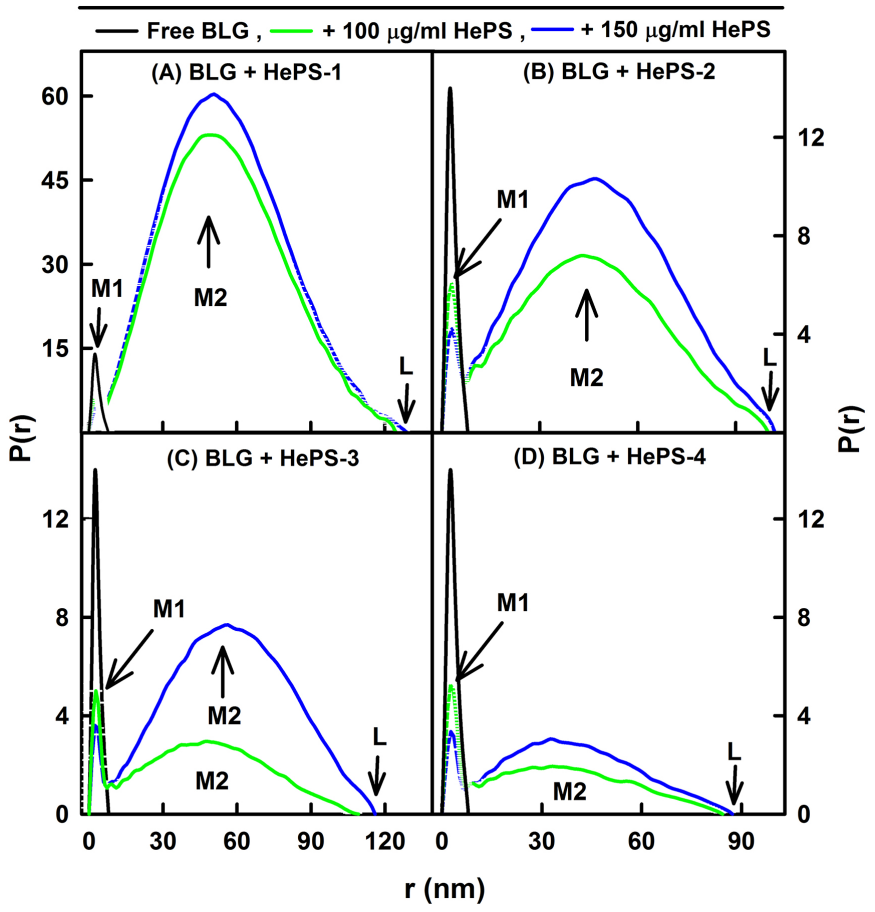

Figure 4 


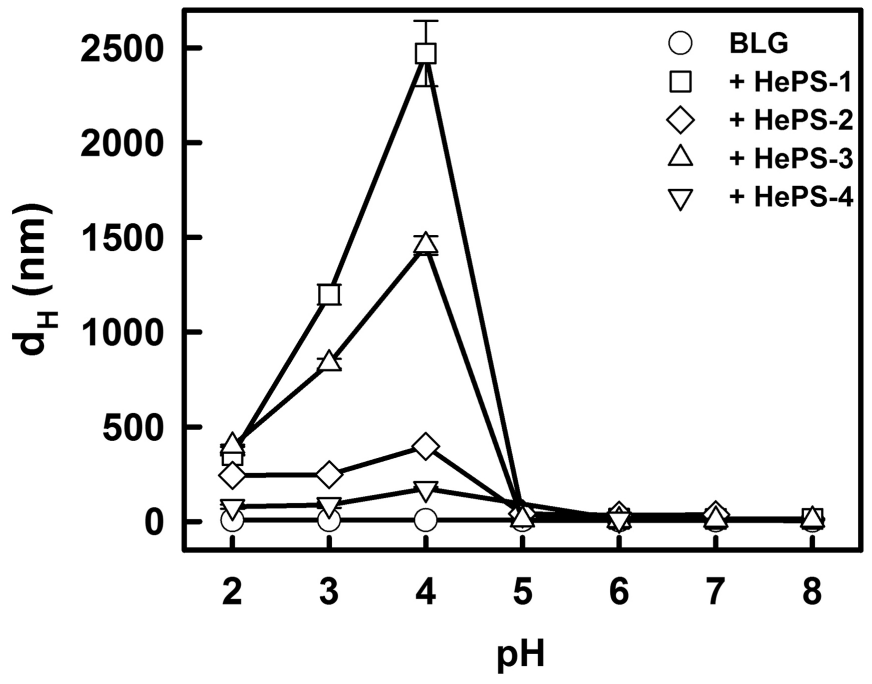

Figure 5 


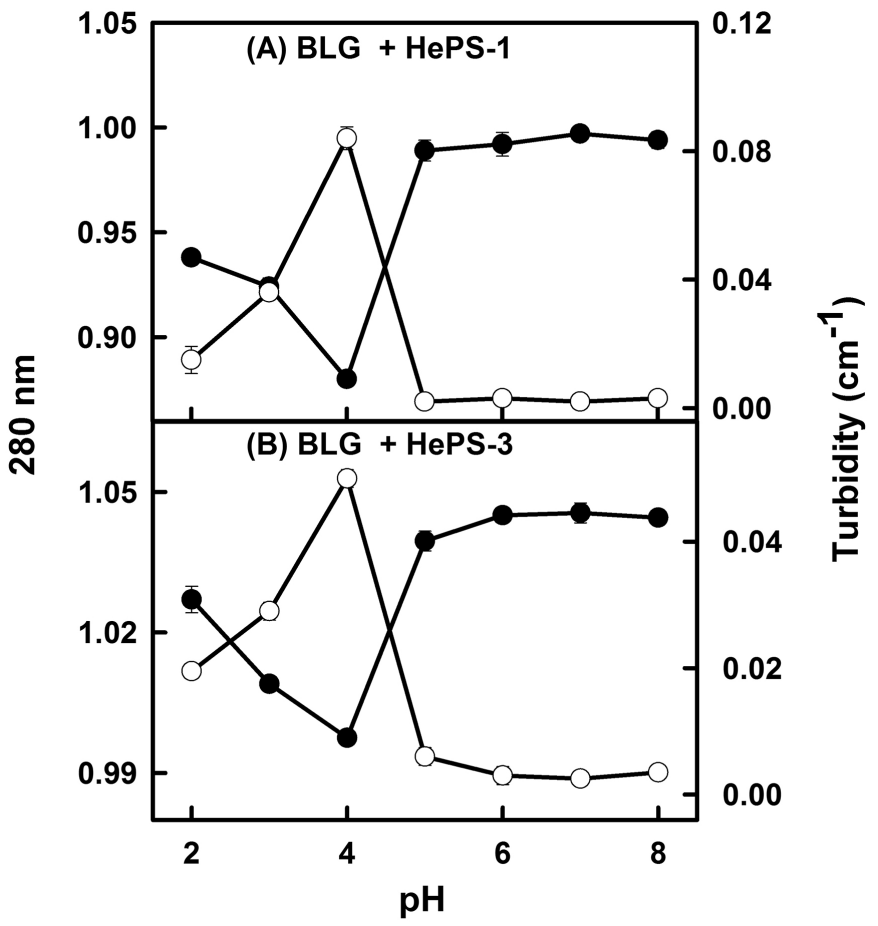

Figure 6 


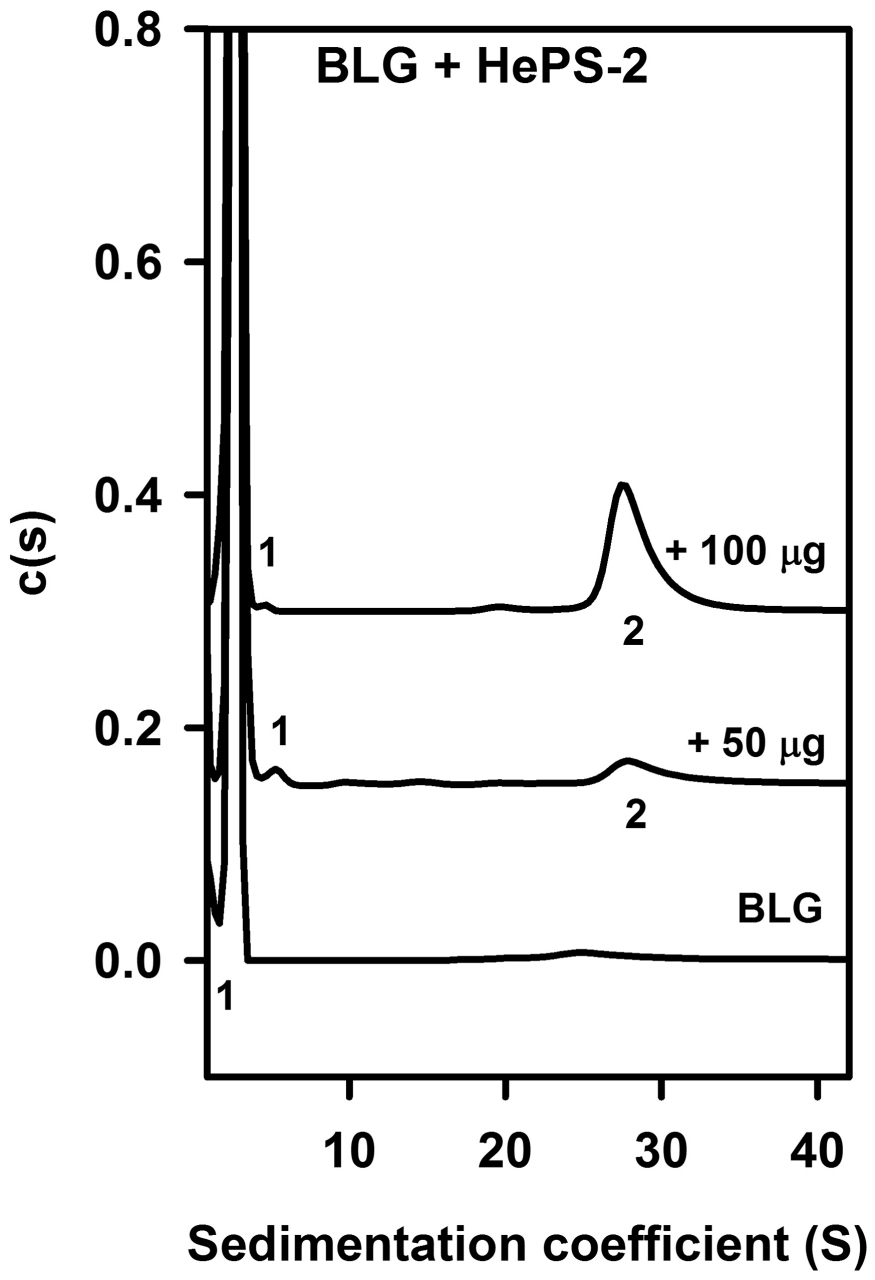

Figure 7 